\title{
Study of a form of pulverulent cataract in a large kindred
}

\author{
M STABILE*, A AMORIELLO,+ S CAPOBIANCO,+ M L CAVALIERE*, \\ N CONTE†, C DE ROSA+, S RUOPPO+, V SORRENTINO+, AND V VENTRUTO* \\ From* the Servizio di Genetica Medica, and $\uparrow$ Servizio di Immunoematologia, Ospedale A Cardarelli; and \\ $\ddagger$ Divisione Oculistica, Ospedale Santobono, Naples, Italy.
}

SUMMARY A large kindred (64 members in four generations), affected by a form of apparently congenital pulverulent cataract, was studied for linkage of its gene locus with that of the Fy blood group. No indication of linkage was found. The involvement of the cortex distinguishes this form from the zonular pulverulent cataract (total nuclear) of Nettleship and Ogilvie, ${ }^{1}$ the locus of which is probably linked with Fy. A correlation between morphological and genetic heterogeneity, based on the linkage with Fy, cannot be established because of the scarcity of published data.

Various forms of congenital pulverulent cataract have been described. The form, named by Nettleship and Ogilvie ${ }^{1}$ as 'congenital pulverulent zonular cataract', had opacities limited to the nucleus and was non-progressive. Renwick and Lawler, ${ }^{2}$ reinvestigating the family of Nettleship and Ogilvie, found a probability of about $98 \%$ that the locus was closely linked to the locus for the Duffy (Fy) blood group. Other forms of congenital pulverulent cataract have been described with a variable distribution of opacities. Clear linkage with Fy has not been confirmed in all the affected families. ${ }^{34} \mathrm{We}$ have studied the possible linkage with Fy in a large kindred of 64 members affected by a form of congenital pulverulent cataract.

\section{Clinical description}

The subjective perception of impairment of ocular vision begins in the second decade of life, although opacities are detectable from infancy, allowing us to presume that the disease is congenital in the family. The disease is therefore probably progressive, at least during early childhood. All the adult subjects of our family have been operated on, so that a greater opacity in adults compared with children cannot be confirmed. The beginning of the vision disturbance and the age of detection depend upon a series of factors (educational attainments, socioeconomic status, standard of medical care), which

Received for publication 8 December 1982.

Accepted for publication 1 April 1983. make it hard to consider a late clinical onset as a reliable criterion for progression of the disease.

Slit-lamp microscopy (fig 1) in the affected members of the family showed diffuse fine opacities in both the nucleus and the cortex of the lens with the pattern of pulverulent cataract. Anterior subcapsular opacities were present in only one patient.

\section{Fy antigen determination}

The Fy phenotype was assigned by the indirect antihuman globulin method. The antisera anti-Fy(a) and anti-Fy(b), produced by Ortho Diagnostic (Raritan, New Jersey, USA), were used.

Three genotypes were considered: Fya Fya (phenotype $\mathrm{Fy}(\mathrm{a})$ ), $\mathrm{Fy}^{\mathrm{b}} \mathrm{Fy}^{\mathrm{b}}$ (phenotype $\mathrm{Fy}(\mathrm{b})$ ), and $\mathrm{Fy}^{\mathrm{a}} \mathrm{Fy}^{\mathrm{b}}$ (phenotype $F y(a b))$. The alleles non-a, non-b $\left(F y^{c}\right)$ are confined to and are common in Negroes. ${ }^{5}$ On the basis of 25 blood group screening programmes in continental Italy and Sardinia, ${ }^{6}$ this allele $\left(F^{c}{ }^{c}\right)$ would not be present in the Italian population and its presence in the Sicilian population would be a sporadic event. ${ }^{7}$

\section{Linkage analysis}

The method of Morton ${ }^{8}$ was adopted to calculate the lod score (z) for the informative matings in the pedigree. The analysis of the pedigree (fig 2) shows that only the following matings can be considered: the mating of III.4, this subject being a double heterozygote with both coupling and repulsion phases being possible (the two children IV.7 and IV.8 are 


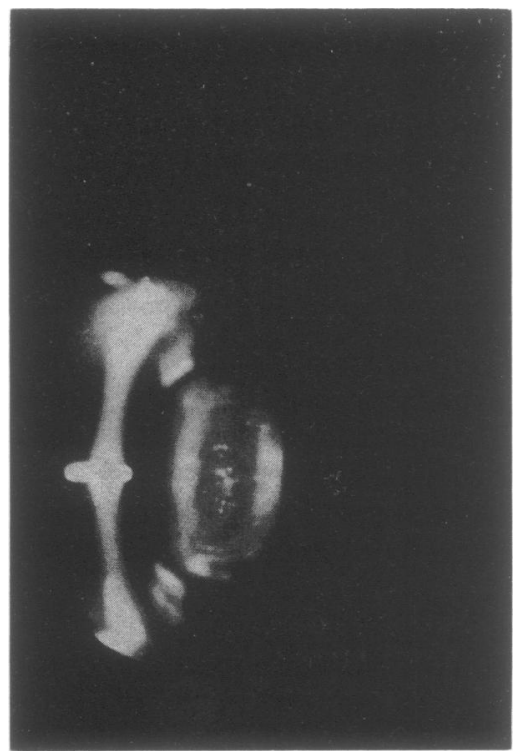

both informative); the mating of III.8, this subject being a double heterozygote with obligatory coupling phase (only the children IV.14 and IV.15 are informative); and the mating of III.13, this subject being a double heterozygote with obligatory coupling phase (all the children are informative).

TABLE The lod scores progressively increase for $\theta \rightarrow 0.5$. This trend is in favour of independent assortment $(\theta=0.5)$ against close linkage.

\begin{tabular}{ll}
\hline$\theta$ & $z$ \\
\hline 0 & -00 \\
0.05 & -2.606 \\
0.1 & -1.57 \\
0.15 & -0.940 \\
0.2 & -0.572 \\
0.25 & -0.324 \\
0.3 & -0.157 \\
0.35 & -0.051 \\
0.4 & +0.008 \\
0.45 & +0.027 \\
0.5 & 0 \\
\hline
\end{tabular}

FIG 1 Slit lamp microscopy shows'diffuse fine opacities in both the nucleus and the cortex of the lens.

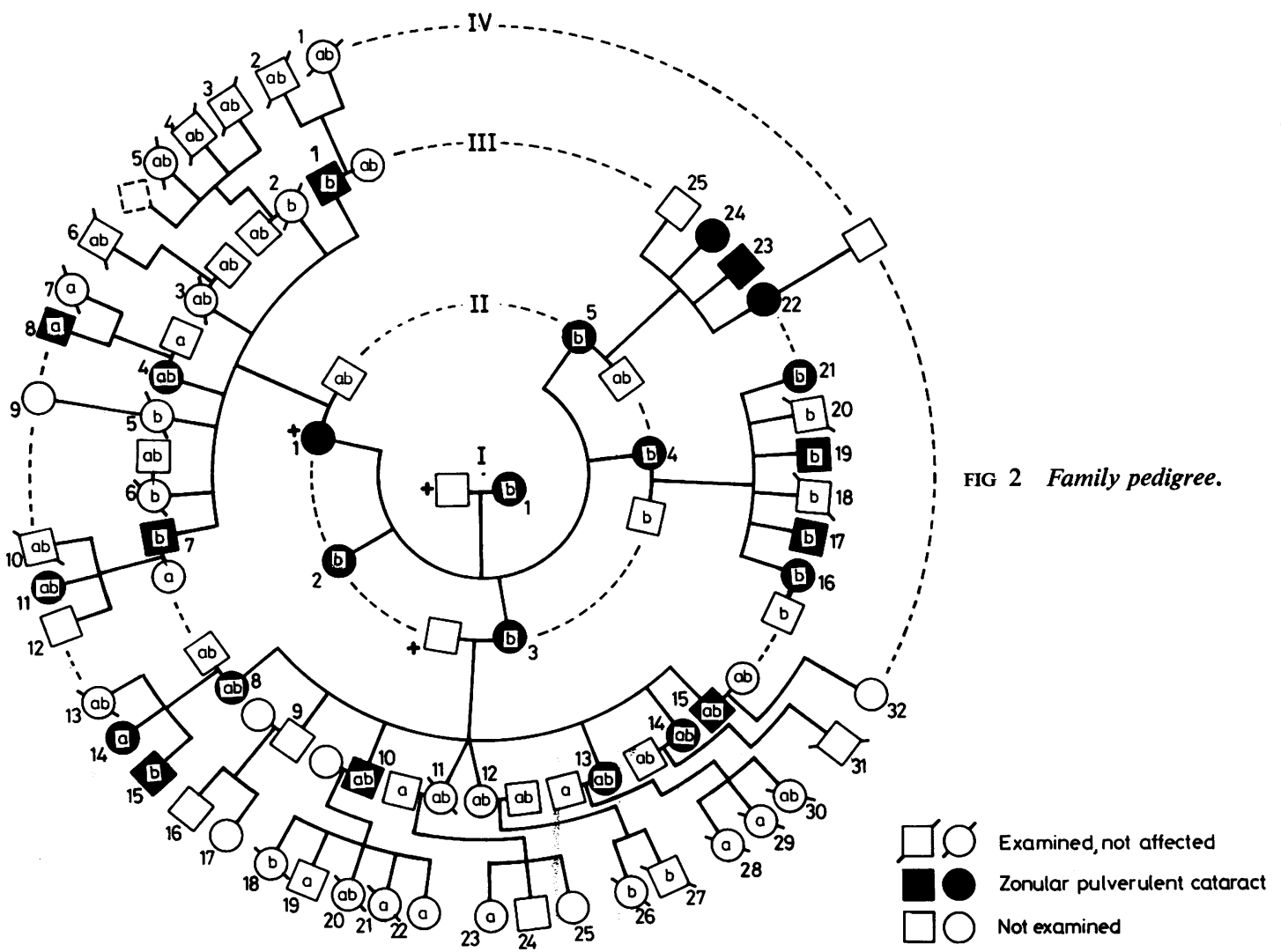


The scores for the various recombination fractions $(\theta)$ in steps of 0.05 , between 0 and 0.5 , and the corresponding antilog of $\mathrm{z}$ are reported in the table. ${ }^{9}$

\section{Discussion}

Recombinants were present in all the informative matings, that is, four out of the nine informative subjects. Statistical analysis confirms the low probability of linkage $(<1 \%)$.

Morphological heterogeneity as regards the cataract pattern is present in various families reported. ${ }^{3}$ The opacity in most members of the family of Nettleship and Ogilvie ${ }^{1}$ was limited to the nucleus (total nuclear cataract), but the involvement of the nucleus, cortical fine opacities, and incomplete riders were present in some other families. Is this phenotypical variability accompanied by a corresponding genetic heterogeneity? A clear cut correlation between the morphology of cataract and linkage with Fy has not yet emerged from the sample of families reported.

Considering genetic heterogeneity with a very similar phenotype, one must be cautious when collecting different families for the calculation of linkage. To calculate the lod scores by adding the scores of different families is perhaps justified only for a group of families with the same ancestral origin.

We thank Signore Giulio Attilio Rossi for assistance with the figures.

\section{References}

1 Nettleship E, Ogilvie FM. A peculiar form of hereditary congenital cataract. Trans Ophthalmol Soc UK 1906;26: 191-206.

2 Renwick JH, Lawler SD. Probable linkage between a congenital cataract locus and the Duffy blood group locus. Ann Hum Genet 1963;27:67-84.

3 McKusick VA. Mendelian inheritance in man. 5th ed. Baltimore: Johns Hopkins University Press, 1978.

4 Renwick JH. Eyes on chromosomes. J Med Genet 1970; 7:239-43.

5 Sanger R, Race RR, Jack J. The Duffy blood groups of New York Negroes: the phenotype Fy(a-b-). Br J Haematol 1955;1:370.

6 Bargogna M. Rapporto sulla distribuzione della frequenza genetica dei principali marcatori eritrocitari e loro uso per l'accertamento di paternità. Riv Med Legale 1979;1: 535-66.

7 Sandler SG, Schilirò G, Russo A, Musumeci S, Rachmilewitz AE. Blood group phenotypes and the origin of sickle cell haemoglobin in Sicilians. Acta Haematol $1978 ; 60: 350-7$.

8 Morton NE. Sequential tests for the detection of linkage. Am J Hum Genet 1955;7:277-318.

9 Maynard-Smith S, Penrose LS, Smith CAB. Mathematical tables for research workers in human genetics. London: Churchill, 1962.

Correspondence and requests for reprints to Professor V Ventruto, Servizio di Genetica Medica, Ospedale A Cardarelli, 80100 Naples, Italy. 